American Journal of Pharmacology and Toxicology 2 (4): 164-169, 2007

ISSN 1557-4962

(C) 2007 Science Publications

\title{
Studies on Bioemulsifier Production by Bacillus licheniformis PTCC 1595
}

\author{
${ }^{1,2}$ Gholamreza Dehghan Noudeh, ${ }^{1}$ Mohammad Hasan Moshafi, \\ ${ }^{1}$ Payam Khazaeli and ${ }^{3}$ Farideh Akef \\ ${ }^{1}$ Department of Pharmaceutics, School of Pharmacy, \\ ${ }^{2}$ Pharmaceutics Research Center, \\ Kerman University of Medical Sciences, Kerman, Iran \\ ${ }^{3}$ Pharmacist
}

\begin{abstract}
Surfactants are amphipathic molecules which reduce surface and interfacial tensions and widely used in pharmaceutical, cosmetic, food and petroleum industries. Biosurfactants are the structurally diverse group of surface-active molecules synthesized by microorganisms. There are several advantages for biosurfactants in contrast with chemical surfactants, such as lower toxicity; higher biodegradability; better environmental compatibility; higher foaming; high selectivity and specific activity at extreme temperatures, $\mathrm{pH}$ and the ability to be synthesized from renewable feedstock. In the present study, the production of bioemulsifer by Bacillus licheniformis PTCC 1595 has been studied. B. licheniformis was grown in the nutrient broth medium and bioemulsifer production was evaluated every $24 \mathrm{~h}$ by surface tension and emulsification index (E24). Then B. licheniformis PTCC 1595 was grown in nutrient broth with different conditions in order to get maximum production of bioemulsifer. The best culture medium was found to be nutrient broth medium supplemented with starch, $\mathrm{Fe}^{2+}, \mathrm{Mn}^{2+}$ and olive oil. After growing the bacteria, the microbial biomass was removed from the supernatant by acidic precipitation method. Its amphipathic structure was established by biochemical and spectroscopy methods and it was confirmed lipopeptide structure.
\end{abstract}

Key words: Bacillus licheniformis, bioemulsifer, surface tension, emulsification index

\section{INTRODUCTION}

Microbial-derived surfactants are amphipatic molecules produced by a wide variety of bacteria, yeasts and filamentous fungi. Increasing environmental concern had led to consider biological surfactants as alternative to chemical manufactured compounds. The most important advantage of biosurfactants when compared to synthetic surfactants is their ecological acceptance, owing to their low toxicity and biodegradable nature ${ }^{[1]}$. Another advantage of biosurfactants is that they can be modified by biotransformation to generate new products for specific requirements ${ }^{[2]}$. Microbial surfactants are complex molecules, comprising a wide variety of chemical structures, such as glycolipids, lipopeptides, fatty acids, polysaccharide-protein complexes, peptides, phospholipids and neutral lipids ${ }^{[3]}$. Potential applications of biosurfactants include emulsification, phase separation, wetting, foaming and surface activity that can be exploited in food, oil, cosmetic and pharmaceutical industries ${ }^{[4]}$. In the environmental sector, microbial surfactants show promising applications in bioremediation and waste treatment to remove hazardous materials ${ }^{[5]}$. Bacillus licheniformis produces a lipopeptide called lichenysin. Lichenysin is a cyclic lipopeptide and belongs to the most effective biosurfactant discovered so far ${ }^{[6]}$. The lipopeptide were found to be a mixture of four closely related compounds. The lipophilic part consisting of $i_{-},{ }^{-{ }^{n}} \mathrm{C} 14$ or $i^{-}, a_{i-}$ C15 $\mathrm{B}-\mathrm{OH}$ fatty acids was linked to the hydrophilic peptide moiety, which contained seven amino acids (Glu, Asp,Val, three Leu and Ile ) by a lactone linkage ${ }^{[7]}$. The lipopeptide showed activity against a variety of yeast strains. Growth of the gram negative bacteria Pseudomonas aeruginosa and Escherichia coli was inhibited by a minimal concentration of $1 \mathrm{mg} \mathrm{mL}^{-1}$. Bioemulsifer produced by B. licheniformis JF-2 exhibits a critical micelle concentration of $10 \mathrm{mg} \mathrm{L}^{\Gamma 1}$ and reduces the interfacial tension against decane to $6 \times 10^{-3}$ dyne $\mathrm{cm}^{-1}$, which is one of the lowest interfacial tensions ever reported for a microbial surfactant ${ }^{[8]}$.

Corresponding Author: Gholamreza Dehghan Noudeh, Department of Pharmaceutics, School of Pharmacy, Kerman University of Medical Sciences, Kerman, Iran 
About $15 \mathrm{mg} \mathrm{L}^{-1}$ of the purified lipopeptide product decreased the surface tension of water from 72 $27 \mathrm{mN} \mathrm{m}^{-1[9]}$.

The strain Bacillus licheniformis D-13 produces three hydrophobic peptides (amoebicins d13-A, d13-B and $\mathrm{d} 13-\mathrm{C}$ ) that elicit antiamoebic activity against human-pathogenic and nonpathogenic species of Naegleria and have a broad spectrum of antibacterial activity. Amoebicin d13-B causes lysis of amoebae through disorganization of the cell membrane. It also induces permeability to $86 \mathrm{Rb}$ and membrane disruption in asolectin vesicles ${ }^{[10]}$.

In this study, the production of bioemulsifer by Bacillus licheniformis PTCC 1595 and some of its properties were determined by using physicochemical methods.

\section{MATERIALS AND METHODS}

Test organism: The B. licheniformis PTCC 1595 was obtained from the Persian Culture Type Collection, Tehran, Iran. The strain was streaked on the surface of nutrient agar plates (HiMedia Laboratories Limited, Mumbai, India). After incubation at $37^{\circ} \mathrm{C}$, distinct colonies were isolated ${ }^{[9]}$.

Hemolytic activity: Isolated strains were screened on blood agar plates (Merck) containing 5\% (v/v) sheep blood and incubated at $37^{\circ} \mathrm{C}$ for $48 \mathrm{~h}$. Hemolytic activity was detected as the presence of a definite clear zone around a colony ${ }^{[11]}$.

Surface activity measurement: Surface tension and critical micelle dilution $\left(\mathrm{CMD}^{-1}\right.$ and $\left.\mathrm{CMD}^{-2}\right)$ were determined with a duNouy Tensiometer (Tensiometer K100, KRUSS). All measurements were made on supernatant. $\mathrm{CMD}^{-1}$ and $\mathrm{CMD}^{-2}$ measurements were performed by measuring the surface tension of 10-times and 100-times diluted supernatant. Negative control consisted of sterile culture medium plus B. licheniformis PTCC 1595 (an inoculum), at zero time ${ }^{[11,12]}$.

Emulsification test: For estimation of the emulsification index, $5 \mathrm{~mL}$ of liquid paraffin was added to $5 \mathrm{~mL}$ of supernatant in a graduated tube and vortexed at high speed for $2 \mathrm{~min}$. The emulsion stability was determined after $24 \mathrm{~h}$. The $\mathrm{E}_{24}$ was calculated by measuring the emulsion layer formed ${ }^{[12-14]}$.

Optimization of Growth conditions: $B$. licheniformis PTCC 1595 was initially grown in $500 \mathrm{~mL}$ Erlenmeyer flasks, each containing $100 \mathrm{~mL}$ nutrient broth medium. The flasks were incubated at $37^{\circ} \mathrm{C}$ in a shaker incubator
(F.F-81, Pars Azma CO.) at 250 rpm. In some experiments, B. licheniformis was grown in nutrient broth with different conditions (aeration rates, temperatures and times of incubation) and additives such as paraffin oil, castor oil, almond oil, olive oil, starch and trace metal cations $\left[\mathrm{MnSO}_{4}, \mathrm{FeSO}_{4}, \mathrm{MgSO}_{4}\right.$, $\mathrm{CaCl}_{2}$ respectively] $(0.3 \mathrm{w} / \mathrm{v}, 0.001 \mathrm{w} / \mathrm{v}, 0.025 \mathrm{w} / \mathrm{v}$ and $0.01 \% \mathrm{w} / \mathrm{v}$ ) to the nutrient broth medium in order to get maximum production of bioemulsifer. Samples were withdrawn every $24 \mathrm{~h}$ (five cultures for each time) to analyze the surface activity, emulsification index and therefore to select the best conditions and additives for bioemulsifer production ${ }^{[7,8,13,15]}$.

Isolation of bioemulsier and partial purification: After the bacterial cells were removed from the liquid culture by centrifugation (13000 g, $15 \mathrm{~min})$ in a HEPTICH centrifuge mod., the crude bioemulsifer was isolated by adding concentrated $\mathrm{HCl}$ to the supernatant. A flocculated precipitate was formed at $\mathrm{pH} 2.0$ that could be collected by centrifugation (20000 g, $20 \mathrm{~min})$. The precipitate was dried under vacuum in dessicator and kept overnight at $4^{\circ} \mathrm{C}$. The crude product was resuspended in dichloromethane. After stirring for one night, the suspension filtered through Whatman No. 1 filter paper to remove the coarse impurities. The filtrate was extracted twice with equal volumes of distilled water $(\mathrm{pH} 8.0)$ while stirring for $20 \mathrm{~min}$. After this period, it was left $3 \mathrm{hrs}$ in a separating funnel to allow the two phases to separate. The aqueous phases containing the bioemulsifer were collected and then were lyophilized overnight ${ }^{[3,12,13]}$.

Circular Dicroism (CD) spectroscopy: CD spectrum was measured at $25^{\circ} \mathrm{C}$ using an AVIV model $62 \mathrm{~A}$ DS spectroscopic measurement was carried out in a $1 \mathrm{~mm}$ path-length cuvette ${ }^{[12]}$.

Infrared analysis: Infrared (IR-470, Shimadzu Corporation, Japan) spectroscopy was used to confirm exact structure $\mathrm{o}$ the bioemulsifer obtained from B. licheniformis PTCC 1595. IR spectera were collected between 400 and 4000 wave numbers $\left(\mathrm{cm}^{-1}\right)^{[6,7]}$.

UV spectroscopy: The sample was dissolved in dichloromethane and UV spectra were obtained between 200-450 nm, using a UV-Visible Spectrophotometer (UV-2100, Shimadzu Corporation,

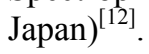

Identification of fatty acid: The bioemulsifer was hydrolysed with $6 \mathrm{M} \mathrm{HCl}$ at $110^{\circ} \mathrm{C}$ for $20 \mathrm{~h}$ and the lipid moiety was subsequently separated by extraction with chloroform. Several drops of bromine water were then added to the extract ${ }^{[7]}$. 
Identification of amino acids: Ninhydrin and biuret reactions were used in order to identify the amino acids. The ninhydrin reagent was added to the sample. A deep blue color developed after the heating of amino acid or peptide with ninhydrin. The biuret reagent was then added to the sample. A positive result was then indicated by a violet or pink ring, due to the reaction of peptide bond proteins or short-chain polypeptides, respectively. Such a result would not occur in the presence of free amino acids ${ }^{[6,12]}$.

\section{RESULTS AND DISCUSSION}

Bioemulsifer production: The Screening of bioemulsifer-producing microorganisms is generally carried out using monitoring parameters that estimate surface activity, emulsifying property and hemolytic capacity. In the present study, these parameters were evaluated as potential predictors of surfactantproducing bacteria.

The hemolytic effect was observed for B. licheniformis PTCC 1595 (Fig. 1). Bioemulsifierproducing capacity in liquid medium is associated with reduction of surface tension ${ }^{[16]}$. B.licheniformis PTCC 1595 was cultured in nutrient broth and bioemulsifier production, as evident from surface tension lowering (Table 1), started from first day and continued until 48 $\mathrm{h}$ of growth. growth. $\mathrm{CMD}^{-1}$ and $\mathrm{CMD}^{-2}$ values (Table 1) followed a similar pattern as surface tension lowering. $\mathrm{CMD}^{-1}$ and $\mathrm{CMD}^{-2}$ measurements were performed by measuring the surface tension of 10-times and 100-times diluted cell-free broth ${ }^{[11,12]}$.

Maximum of bioemulsifer production was achieved in $48 \mathrm{~h}$ of incubation and CMD values (Fig. 2) were minimal at this point. Emulsification index values followed a similar pattern as surface tension lowering (Table 2 and Fig. 3). According to these data, $37^{\circ} \mathrm{C}$ and $300 \mathrm{rpm}$ were selected as best conditions (Fig. 4 and 5) ${ }^{[7]}$.

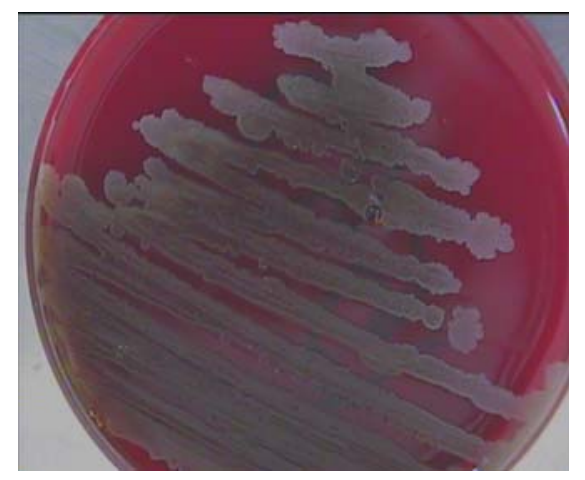

Fig. 1: Colonies of B. licheniformis PTCC 1595 on blood agar
The production yield of bioemulsifer was improved by addition of $\mathrm{FeSO}_{4}, \mathrm{MnSO}_{4}$ and starch while $\mathrm{CaCl}_{2}$ and $\mathrm{MgSO}_{4}$ decreased it (Fig. 6). The addition of hydrocarbons, such as almond, castor oil and olive oil to the culture medium increased the bioemulsifer production while maximum of yield was achieved with olive oil (Fig. 7) ${ }^{[7,8]}$.

Table 1: Surface activity studies, (Surface Tension); ST; (Critical micelle dilution) ${ }^{-1} ; \mathrm{CMD}^{-1}$ and (Critical micelle dilution) ${ }^{-2}$; $\mathrm{CMD}^{-2}$; results for supernatant of $B$. licheniformis PTCC 1595 , grown in nutrient broth medium $\left(37^{\circ} \mathrm{C}, 250 \mathrm{rpm}\right)$

\begin{tabular}{lcll}
\hline $\begin{array}{l}\text { Time } \\
(\mathrm{h})\end{array}$ & $\begin{array}{l}\text { Surface tention } \\
\left(\mathrm{mNm}^{-1}\right) \pm \mathrm{SD}\end{array}$ & $\begin{array}{l}\mathrm{CMD}^{-1} \\
\left(\mathrm{mNm}^{-1}\right) \pm \mathrm{SD}\end{array}$ & $\begin{array}{l}\mathrm{CMD}^{-2} \\
\left(\mathrm{mNm}^{-1}\right) \pm \mathrm{SD}\end{array}$ \\
\hline 0 & $67.43 \pm 0.0223$ & $68.37 \pm 0.0234$ & $69.21 \pm 0.0561$ \\
24 & $55.52 \pm 0.0339$ & $60.35 \pm 0.0190$ & $66.68 \pm 0.0122$ \\
48 & $46.51 \pm 0.1504$ & $56.48 \pm 0.1213$ & $61.82 \pm 0.1999$ \\
72 & $59.46 \pm 0.1110$ & $66.47 \pm 0.1232$ & $70.32 \pm 0.0115$ \\
96 & $60.17 \pm 0.2132$ & $68.79 \pm 0.0333$ & $70.58 \pm 0.0277$ \\
120 & $60.54 \pm 0.0314$ & $67.33 \pm 0.0212$ & $70.38 \pm 0.0121$ \\
\hline
\end{tabular}

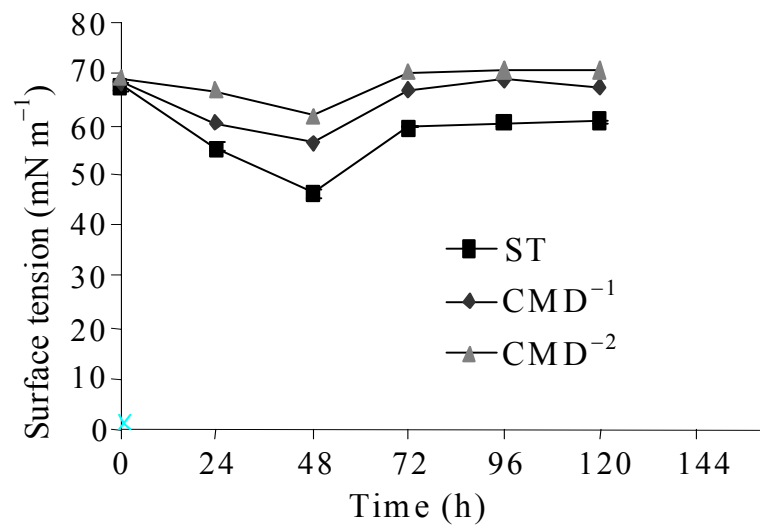

Fig. 2: Surface activity profile for supernatant of $B$. licheniformis PTCC 1595. $\left(37^{\circ} \mathrm{C}, 250 \mathrm{rpm}\right)$

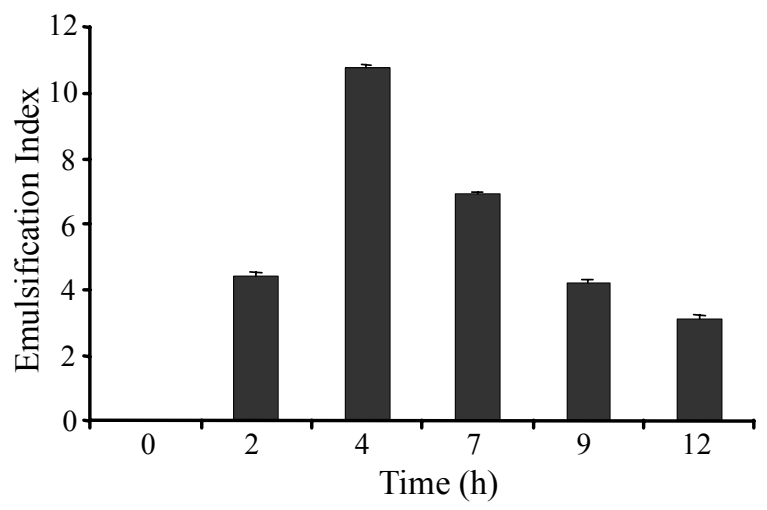

Fig. 3: Emulsification index; $E_{24}$, graph of $B$. licheniformis PTCC 1595 with different times of incubation $\left(37^{\circ} \mathrm{C}, 250 \mathrm{rpm}\right)$ 
Table 2: Emulsification index; $\mathrm{E}_{24}$; results for supernatant of $B$. licheniformis PTCC 1595 grown in nutrient broth medium $\left(37^{\circ} \mathrm{C}, 250 \mathrm{rpm}\right)$

\begin{tabular}{ll}
\hline Time $(\mathrm{h})$ & Emulsification index $\left(\mathrm{E}_{24}\right) \pm \mathrm{SD}$ \\
\hline 0 & $0 \pm 0.00$ \\
24 & $4.23 \pm 0.12$ \\
48 & $10.97 \pm 0.11$ \\
72 & $6.63 \pm 0.19$ \\
96 & $5.34 \pm 0.17$ \\
120 & $4.43 \pm 0.12$ \\
\hline
\end{tabular}

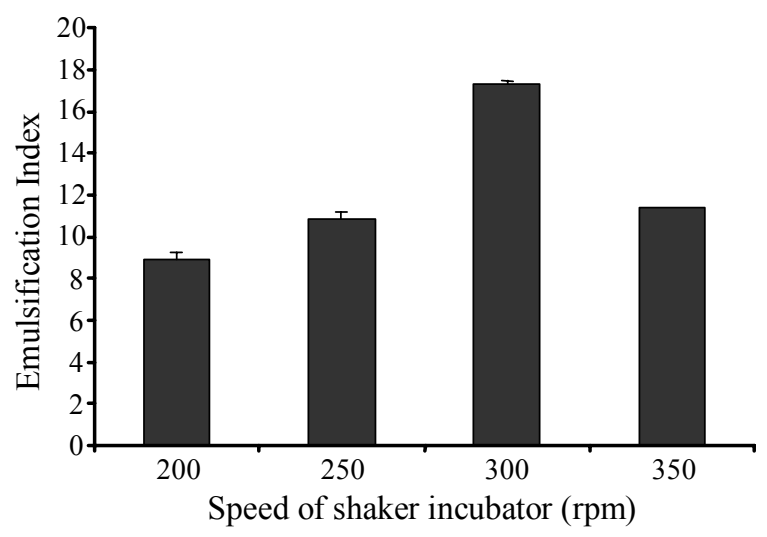

Fig. 4: Emulsification index; $\mathrm{E}_{24}$, graph of $B$. licheniformis PTCC 1595 with different aeration rates $\left(37^{\circ} \mathrm{C}, 48 \mathrm{~h}\right)$

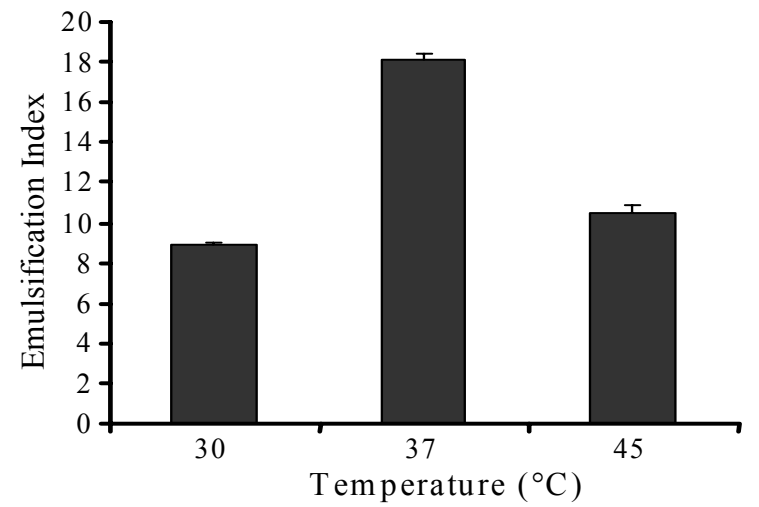

Fig. 5: Emulsification index; $\mathrm{E}_{24}$, graph of $B$. licheniformis PTCC 1595 with different temperatures (300 rpm, $48 \mathrm{~h}$ )

Characterization of bioemulsifer: $\mathrm{IR}\left(\mathrm{KBr}, \mathrm{Cm}^{-1}\right)$ : 3312 (stretching mode of N-H), 1647 (stretching mode of the $\mathrm{C}=\mathrm{O}$ ) 1539 (deformation mode (combined C-N stretching mode) of the NH bond), 2966, 1456 and 1371 (aliphatic chains (-CH3, -CH2-), 1740-1680 (lactone carbonyl), (Fig. 8). A far UV CD spectrum of bioemulsifer showed behavior $\beta$-sheet form in phosphate buffer solution (Fig. 9). The ease of micelle formation may reflect the ease of piling of bioemulsifer molecules organized by $\beta$-sheet formation.

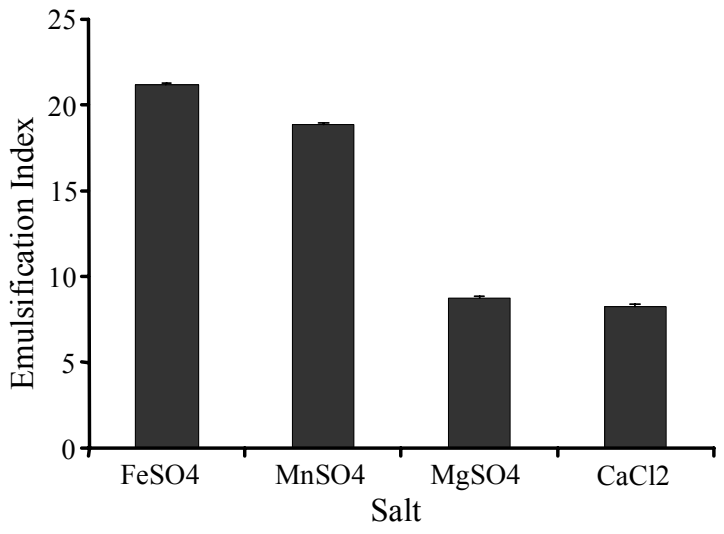

Fig. 6: Emulsification index; $\mathrm{E}_{24}, \quad$ graph of B. licheniformis PTCC 1595 with different salts (300 rpm, $48 \mathrm{~h}, 37^{\circ} \mathrm{C}$ )

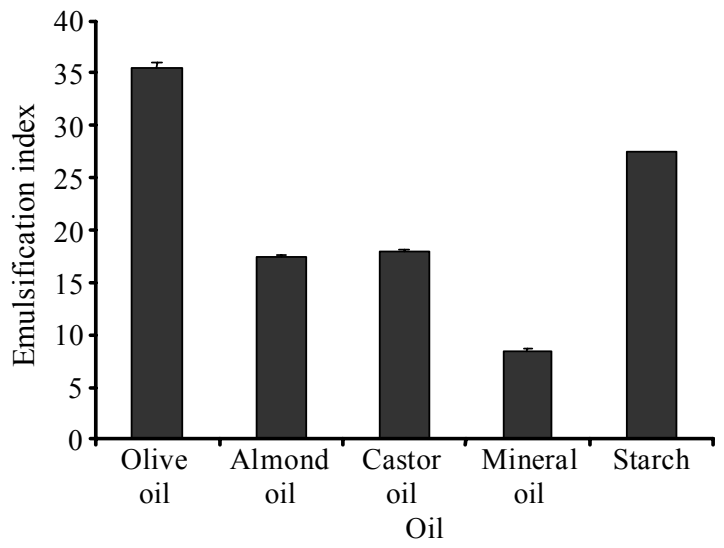

Fig. 7: Emulsification index; $\mathrm{E}_{24}$, graph of $B$. licheniformis PTCC 1595 with different carbon sources $\left(300 \mathrm{rpm}, 48 \mathrm{~h}, 37^{\circ} \mathrm{C}\right)$

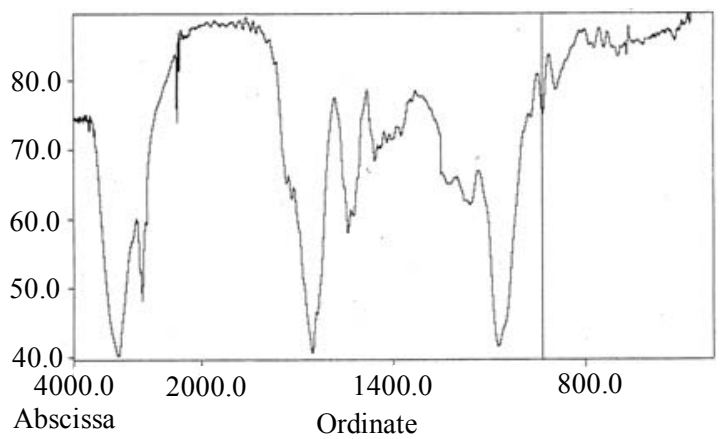

Fig. 8: IR spectrum of bioemulsifer

The exposure of a large number of carboxylic groups on the surface due to $\beta$-sheet organization may contribute to the special behavior of bioemulsifer such as the ease of surface $\beta$-sheet micelles and the ease of surface adsorption ${ }^{[1,16]}$. 
Am. J. Pharm. \& Toxicol., 2 (4): 164-169, 2007

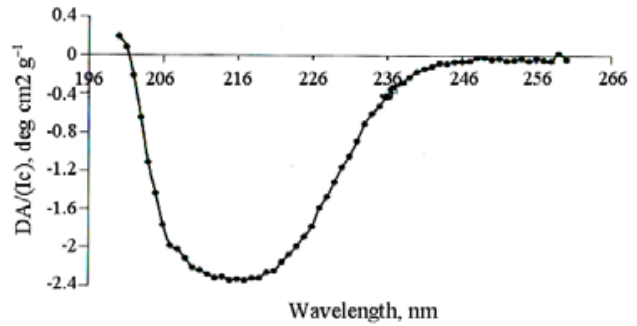

Fig. 9: Far UV CD spectrum of bioemulsifier at $25^{\circ} \mathrm{C}$

On the other hand, presence of peptide bonds was clearly demonstrable from UV spectrum at range $239 \mathrm{~nm}$ that indicated the product was lipopeptide which has confirmed previously. These results indicate that the product contains aliphatic hydrocarbobons as well as a peptide-like moiety. Bromine water reaction was negative; indicating which the fatty acid chain was saturation. Ninhydrin reaction was negative, indicating the peptide has a blocked N-terminal. Biuret reaction was positive indicating for polypeptide. The results indicate that the bioemulsifer has lipopeptide structure. Hemolytic measurement showed that as same as synthetic surfactants it was able to rupture erythrocyte and therefore could be used as absorption enhancer.

\section{CONCLUSION}

The presence of a lactone ring in bioemulsifer was detected by IR spectrum. The IR spectrum indicated the presence of long chain fatty acids (Fig. 8). UV spectrum indicated the presence of peptide groups in the product. A far UV CD spectrum of bioemulsifer showed $\beta$-sheet form behavior (Fig. 9). These results indicate that the product has lipopeptide structure. Therefore, this bioemulsifer with various activities and properties can be used as an interesting compound in the pharmaceutical, industry as well as energy and environmental fields. Due to its low toxicity it could be considered a suitable surfactant in drug formulations.

\section{REFERENCES}

1. Karanth, N.G.K., P.G. Deo and N.K. Veenanadig, 1999. Microbial production of biosurfactants and their importance. Curr. Sci., 77:116-26.

2. Deleu, M. and M. Paquot, 2004. From renewable vegetables resources to microorganisms: New trends in surfactants. Comptes Rendus Chim., 7: 641-646.

3. Banat, I.M., R.S. Makkar and S.S. Cameotra, 2000. Potential commercial applications of microbial surfactants. Applied Microbiol. Biotechnol., 53: 495-508.

4. Makkar, R.S. and S.S. Cameotra, 2002. An update on the use of unconventional substrates for biosurfactant production and their new applications. Applied Microbiol. Biotechnol., 58: 428-434.
5. Mulligan, C.N., 2005. Environmental applications for biosurfactants. Environ. Pollut. 133: 183-98.

6. Yakimov, M.M., K.N. Timmis, V. Wray and H.L. Fredriokson, 1995. Characterization of a new lipopeptide surfactant produced by thermotolerant and halotolerant subsurface Bacillus licheniformis BAS50. Applied Environ. Microbiol., 61: 1706-1713.

7. Jenny, K., O. Kappeli and A. Fiechter, 1991. Biosurfactants from Bacillus licheniformis: structural analysis and characterization. Applied Microbial. Biotechnol., 36: 5-13.

8. Lin, S.C., M.A. Minton, M.M. Sharma and G. Georgiou, 1994. Structural and immunological characterization of a biosurfactant produced by Bacillus licheniformis JF-2. Applied Environ. Microbiol., 60: 31-38.

9. Konz, D., S. Doekel and M.A. Marahiel, 1999. Molecular and biochemical characterization of the protein template controlling biosynthesis of the lipopeptide lichenysin. J. bacteriol., 181: 133-140.

10. Glavez, A., M. Maqueda and P. Cordovilla et al., 1994. Characterization and biological acting against Naegleria fowleri of amoebicins produced by Bacillus licheniformis D-13. Antimicrobial Agents Chemother., 38: 1314-1319.

11. Carrillo, P.G., C. Mardaraz, S.I. Pitta Alvarez and A. Giulietti, 1996. Isolation and selection of biosurfactant producing bacteria. World. J. Microbiol. Biotechnol., 12: 82-84.

12. Dehghan-noudeh, G., M. Housaindokht and B.S. Fazzly Bazzaz, 2005. Isolation, characterization and investigation of surface and hemolytic activities of a lipopeptide biosurfactant produced by Bacillus subtilis ATCC 6633. Microbiol. Soc. Korea, 43: 272-276.

13. Cooper, D.G. and B.G. Goldenberg, 1987. Surfaceactive agents from two Bacillus species. Applied Environ. Microbiol., 53: 224-229.

14. Markkar, R.S. and S.S. Cameotra, 1997. Utilization of molasses for biosurfactant production by two Bacillus strains at thermophilic conditions. JAOCS, 74: 887-889.

15. Lin, S.C., K.G. Lin, C.C. Lo and Y.M. Lin, 1998. Enhanced biosurfactant production by a Bacillus licheniformis mutant. Enzyme. Microbiol. Technol., 23: 267-273.

16. Youssef, N.H., K.E. Duncan and D.P. Nagle et al., 2004. Comparison of methods to detect biosurfactant production by diverse microorganisms. J. Microbiol. Methods, 56: 339-347.

17. Thaniyavarn, J., N. Roongsawang and T. Kameyama et al., 2003. Production and characterization of biosurfactants from Bacillus licheniformis F2.2. Biosci. Biotechnol. Biochem., 67: 1239-1244. 